\title{
Treatment outcome of advanced pancreatic cancer patients who are ineligible for a clinical trial
}

This article was published in the following Dove Press journal:

OncoTargets and Therapy

3 May 2013

Number of times this article has been viewed

\section{Akira Ueda \\ Ayumu Hosokawa \\ Kohei Ogawa \\ Hiroki Yoshita \\ Takayuki Ando \\ Shinya Kajiura \\ Haruka Fujinami \\ Kengo Kawai \\ Jun Nishikawa \\ Kazuto Tajiri \\ Masami Minemura \\ Toshiro Sugiyama}

Department of Gastroenterology and Hematology, Faculty of Medicine, University of Toyama, Toyama, Japan

Correspondence: Ayumu Hosokawa Department of Gastroenterology and Hematology, Faculty of Medicine, University of Toyama, 2630 Sugitani,

Toyama, Toyama 930-0194, Japan

Tel +8I 76434730 I

Fax +8I 764945207

Email ayhosoka@med.u-toyama.ac.jp
Objective: The aim of this study was to evaluate the outcome of patients with advanced pancreatic cancer in clinical practice, and assess whether chemotherapy provided a clinical benefit for patients who did not meet the eligibility criteria of the clinical trial.

Methods: We retrospectively analyzed the medical records of 75 patients who received firstline chemotherapy for pancreatic cancer between April 2006 and September 2011. Patients were treated with gemcitabine (GEM) alone, S-1 (tegafur, gimeracil, and oteracil potassium) alone, or GEM plus S-1. Patients were divided into the clinical trial eligible group (arm eligible) or the ineligible group (arm ineligible). We evaluated the efficacy and the safety of the chemotherapy.

Results: A total of 23 patients out of 75 (31\%) belonged to the ineligible group, for the following reasons: 20 patients had poor performance status, eight had massive ascites, one had synchronous malignancy, and one had icterus. The median progression-free survival (PFS) was 3.5 months, and the median overall survival (OS) was 6.7 months in all patients. In arm eligible, median PFS was 4.5 months, and median OS was 10.5 months. In arm ineligible, median PFS was 1.1 months, and median OS was 2.9 months.

Conclusion: The outcome of the patients who did not meet the eligibility criteria was very poor. It is important to select the patients that could benefit from either chemotherapy or optimal supportive care.

Keywords: gemcitabine, S-1, clinical practice

\section{Introduction}

Pancreatic cancer is the fifth leading cause of cancer-related deaths in Japan. ${ }^{1}$ Despite improved diagnostic and therapeutic techniques, pancreatic cancer has remained a devastating disease with a $5 \% 5$-year survival rate. ${ }^{2}$ The high mortality rate of pancreatic cancer is due to the high incidence of advanced disease at the time of diagnosis, aggressive clinical course, and the lack of adequate systemic therapies. Gemcitabine (GEM) became the reference regimen for advanced pancreatic cancer after a randomized trial showed significant improvement in the median overall survival (OS) as compared with fluorouracil, although the survival gain was modest. ${ }^{3}$ FOLFIRINOX (a combination of oxaliplatin, irinotecan, fluorouracil, and leucovorin) and a combination of GEM and erlotinib showed a significant survival advantage compared with GEM alone in patients with good performance status (PS), but had increased toxicity.,

In the GEST (GEM and S-1 [tegafur, gimeracil and oteracil potassium] Trial), which was the latest Phase 3 trial of GEM plus S-1 (GS) versus S-1 versus GEM, the outcome was relatively good: median progression-free survival (PFS) ranged 
from 4.1 to 5.7 months, and median OS ranged from 8.8 to 10.1 months. ${ }^{6}$ However, chemotherapy was provided for patients who were eligible for the clinical trial as well as for the ineligible patients in clinical practice. There were few studies that evaluated the outcome of the patients who did not met the eligibility criteria of the clinical trial, and little information is available on whether these patients benefited from chemotherapy. GEST was the latest trial, and the test drugs were widely used for pancreatic cancer patients in Japan. Therefore, we analyzed treatment outcome in clinical practice by dividing patients based on whether or not they met the eligibility criteria of the GEST.

\section{Patients and methods}

\section{Patients}

The source of the study was the database of patients treated in our institution. The criteria for inclusion of patients were as follows: 20 years of age or older, clinically diagnosed pancreatic cancer with locally unresectable disease or metastatic lesions at the time of diagnosis or after curative resection, and no prior systematic chemotherapy or radiation therapy. Clinical diagnosis was defined as follows: (1) histologically or cytologically diagnosed adenocarcinoma; (2) typical pancreas tumor by image with metastatic lesions; (3) growing pancreas tumor confirmed by imaging test; (4) accumulation of 18 fluorodeoxyglucose-positron emission tomography suspecting pancreatic cancer.

Patients were divided into the clinical trial eligible group (arm eligible) or the ineligible group (arm ineligible) according to the GEST trial. Arm eligible was selected by the following criteria: Eastern Cooperative Oncology Group (ECOG) PS score of 0 or 1 , oral intake possible, and adequate bone marrow (leukocyte count $>3500 / \mathrm{mm}^{3}$; platelet count $>100,000 / \mathrm{mm}^{3}$ ), liver function (bilirubin $<2.0 \mathrm{mg} / \mathrm{dL}$; GOT (glutamic-oxaloacetic transaminase)/GPT (Glutamicpyruvic transaminase $)<150 \mathrm{U} / \mathrm{L}$ ), and renal function (creatinine clearance rate $>50 \mathrm{~mL} / \mathrm{min}$ ). Exclusion criteria of arm eligible were as follows: a history of another major cancer, active infection, clinically significant cardiovascular disease, evidence of central nervous system metastases, and massive ascites.

\section{Treatment}

Patients were treated with GEM alone, S-1 alone, or GS. The treatment schedule of each therapy was as follows.

1. GEM alone: GEM, at a dose of $1000 \mathrm{mg} / \mathrm{m}^{2}$, was delivered by 30 -minute intravenous infusion weekly for 3 weeks in 4-week courses.
2. S-1 alone: $\mathrm{S}-180 \mathrm{mg} / \mathrm{m}^{2}$ from days 1 to 28 , repeated every 6 weeks.

3. GS: GS consisted of GEM at a dose of $1000 \mathrm{mg} / \mathrm{m}^{2}$, given as a 30-minute intravenous infusion on days 1 and 8 , and oral S-1 at a dose of $60 \mathrm{mg} / \mathrm{m}^{2}$ from days 1 to 14 , repeated every 3 weeks.

When patients were elderly, had poor PS or for other reasons, the dosage of drugs was reduced by the judgment of the attending physician, as appropriate. Treatment was repeated until disease progression, the occurrence of unacceptable toxicity, or the patient's refusal.

\section{Treatment outcome}

Response rate (RR) was evaluated using Response Evaluation Criteria in Solid Tumors (RECIST), version 1.1. Patients without measurable lesions were excluded from the analysis of RR. Adverse events were assessed according to the Common Terminology Criteria for Adverse Events (CTCAE), version 3.0.

\section{Statistical analysis}

Survival was updated on October 2012. The survival time was calculated from the date of treatment initiation to the day on which events were confirmed or to the last date of confirmation of survival. We estimated survival curves using the Kaplan-Meier method and compared them with the log-rank test. The unpaired chi-square test or Student's $t$-test was used for the comparison between groups. All statistical analyses were performed by using JMP version 10 (SAS Institute Inc, Cary, NC, USA), and $P$-values of $<0.05$ (two-sided) were considered to indicate statistical significance.

\section{Results}

\section{Patient characteristics}

We retrospectively analyzed 75 patients who received first-line chemotherapy for pancreatic cancer between April 2006 and September 2011. Table 1 shows the patient characteristics. The median age of the 75 patients was 67 years (range 46-84), and 43 of 75 patients (57\%) were male. Although most patients $55(73 \%)$ had an ECOG PS of $0-1,20$ patients $(27 \%)$ had a poor performance status. A total of 49 patients $(65 \%)$ had pancreas tail cancers, and 59 patients (79\%) had metastatic lesions. A total of 46 patients $(61 \%)$ had a histologically or cytologically confirmed diagnosis of pancreatic cancer. Fifty-three patients $(71 \%)$ had received GEM, 15 patients $(20 \%)$ were treated with GS, and seven patients $(9 \%)$ received S-1, respectively. A total of 52 out of 75 patients $(69 \%)$ met eligibility criteria of arm eligible. 
Table I Patient characteristics

\begin{tabular}{|c|c|c|c|c|}
\hline & $\begin{array}{l}\text { All } \\
(n=75)\end{array}$ & $\begin{array}{l}\text { Arm } \\
\text { ineligible } \\
(n=23)\end{array}$ & $\begin{array}{l}\text { Arm } \\
\text { eligible } \\
(n=52)\end{array}$ & $P$-value \\
\hline \multicolumn{5}{|l|}{ Age - years } \\
\hline Median & 67 & 73 & 62 & \multirow[t]{2}{*}{0.054} \\
\hline Range & $46-84$ & $46-84$ & $50-82$ & \\
\hline \multicolumn{5}{|l|}{ Sex - no (\%) } \\
\hline Male & $43(57)$ & $14(6 \mid)$ & $29(56)$ & \multirow[t]{2}{*}{0.68} \\
\hline Female & $32(43)$ & 9 (39) & $23(44)$ & \\
\hline \multicolumn{5}{|c|}{ ECOG performance status score - no (\%) } \\
\hline 0 & II (I5) & $0(0)$ & II (2I) & \multirow[t]{3}{*}{$<0.000$ I } \\
\hline I & $44(58)$ & $3(13)$ & $41(79)$ & \\
\hline 2 & $20(27)$ & $20(87)$ & $0(0)$ & \\
\hline \multicolumn{5}{|c|}{ Pancreatic tumor location - no (\%) } \\
\hline Head & $26(35)$ & 9 (39) & $17(33)$ & \multirow[t]{2}{*}{0.59} \\
\hline Body & $49(65)$ & $14(6 \mid)$ & $35(67)$ & \\
\hline \multicolumn{5}{|c|}{ Extent of disease - no (\%) } \\
\hline Locally advanced & $16(2 \mid)$ & $2(9)$ & $14(27)$ & \multirow[t]{2}{*}{0.076} \\
\hline Distant metastases & $59(79)$ & $2 I(9 l)$ & $38(73)$ & \\
\hline \multicolumn{5}{|c|}{ No of metastatic sites involved - no (\%) } \\
\hline 1 & $25(33)$ & $4(17)$ & $21(40)$ & \multirow[t]{2}{*}{0.0070} \\
\hline$\geq 2$ & $34(45)$ & $17(74)$ & $17(32)$ & \\
\hline \multicolumn{5}{|l|}{ Diagnosis - no (\%) } \\
\hline Histologically & $46(61)$ & $13(57)$ & $33(63)$ & \multirow[t]{2}{*}{0.57} \\
\hline Clinically & $29(39)$ & $10(43)$ & $19(37)$ & \\
\hline \multicolumn{5}{|l|}{ Chemotherapy - no (\%) } \\
\hline Gemcitabine & $53(7 \mathrm{I})$ & $20(87)$ & $33(63)$ & \multirow[t]{3}{*}{0.070} \\
\hline Gemcitabine + S-I & $15(20)$ & I (4) & $14(27)$ & \\
\hline S-I & 7 (9) & $2(9)$ & $5(10)$ & \\
\hline
\end{tabular}

Abbreviations: ECOG, Eastern Cooperative Oncology Group; S-I, tegafurgimeracil-oteracil potassium.

Twenty-three patients (31\%) belonged to arm ineligible, for the following reasons: 20 patients had poor PS, eight had massive ascites, one had synchronous malignancy, and one had icterus. Comparing the difference in characteristics between arm eligible and arm ineligible, PS and number of metastatic organs were worse in arm ineligible.

\section{Response and survival}

With a median follow-up time of 6.5 months in all patients, the median PFS was 3.5 months, and the median OS was 6.7 months in all patients (Figure 1A). According to eligibility, the median PFS was 1.1 months in the arm ineligible and 4.5 months in the arm eligible $(P<0.0001)$ (Figure 1B). The median OS of the arm ineligible and the arm eligible was 2.9 months and 10.5 months $(P<0.0001)$ (Figure 1C). According to eligibility and treatment group, the response rate was $0 \%$ in the arm ineligible with GEM, $10 \%$ in the arm eligible with GEM, and $46 \%$ in the arm eligible with GS (Table 2). In the arm eligible, median PFS was 4.2 months in GEM and 5.9 months in GS (GEM versus GS; $P=0.77$ ) (Figure 2A). Median OS was 9.6 months in
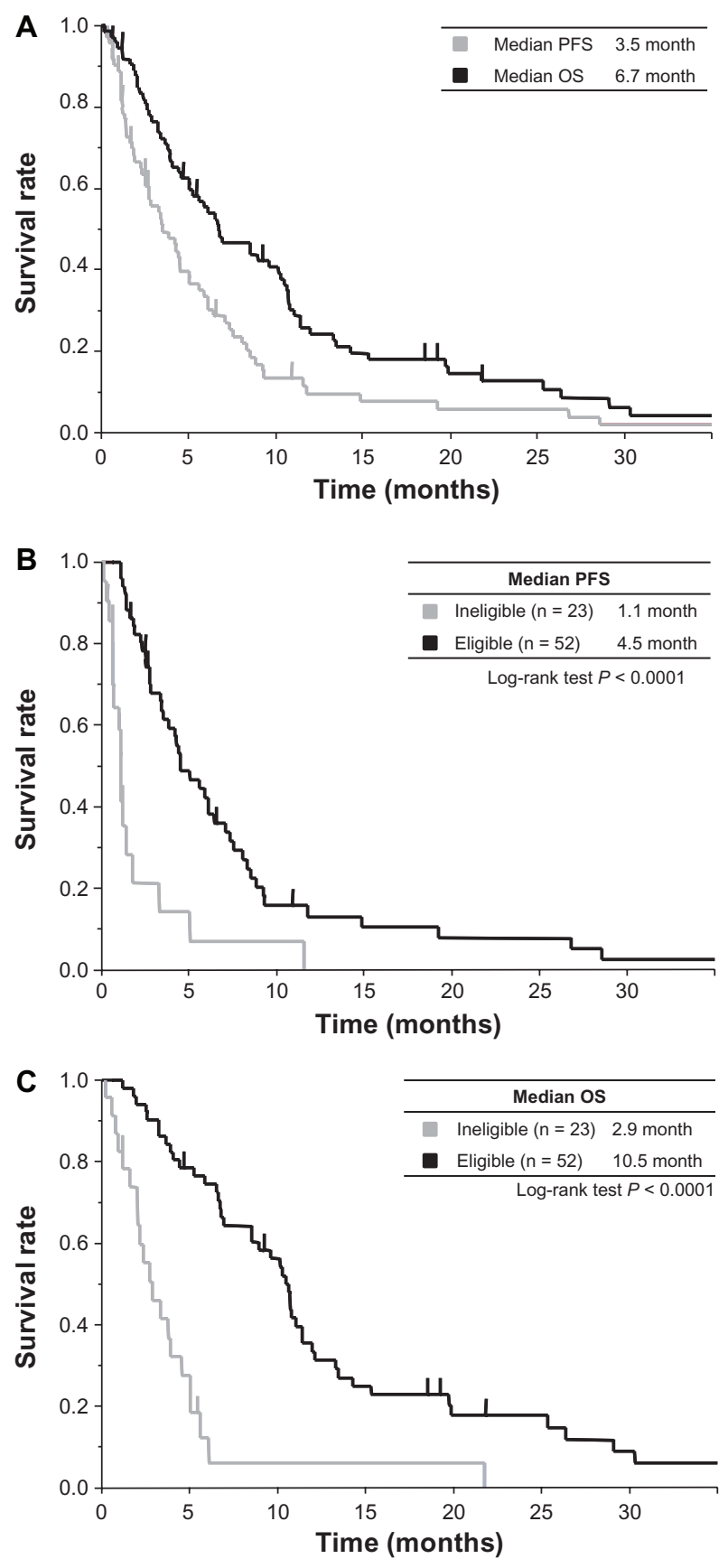

Figure I Kaplan-Meier estimates of PFS and OS in all patients and according to eligibility for clinical trial. (A) PFS and OS in all patients; the median was 3.5 months (gray line) and 6.7 months (black line), respectively. (B) PFS according to eligibility; the median was 1.1 months in arm ineligible (gray line) and 4.5 months in arm eligible (black line). (C) OS according to eligibility; the median was 2.9 months in arm ineligible (gray line) and 10.5 months in arm eligible (black line). Abbreviations: PFS, progression-free survival; OS, overall survival.

GEM and 10.7 months in GS (GEM versus GS; $P=0.92$ ) (Figure 2B).

\section{Adverse events}

Adverse events are summarized in Table 3. Treatment was generally well tolerated in each group. The arm ineligible 
Table 2 Objective responses

\begin{tabular}{llll}
\hline & $\begin{array}{l}\text { Arm ineligible } \\
\text { with GEM } \\
(\mathbf{n = 2 0 )}\end{array}$ & $\begin{array}{l}\text { Arm eligible } \\
\text { with GEM } \\
(\mathbf{n}=\mathbf{3 3})\end{array}$ & $\begin{array}{l}\text { Arm eligible } \\
\text { with GS } \\
(\mathbf{n}=14)\end{array}$ \\
\hline $\begin{array}{l}\text { Could not be } \\
\text { evaluated }\end{array}$ & 12 & 2 & $\mathrm{I}$ \\
$\begin{array}{l}\text { Response - no (\%) } \\
\text { Complete }\end{array}$ & $0(0)$ & $0(0)$ & $0(0)$ \\
$\begin{array}{l}\text { response } \\
\text { Partial response }\end{array}$ & $0(0)$ & $3(10)$ & $6(46)$ \\
$\begin{array}{l}\text { Stable disease } \\
\text { Progressive }\end{array}$ & $2(25)$ & $19(61)$ & $6(46)$ \\
disease & $6(75)$ & $9(29)$ & $1(8)$ \\
Rate of objective response* & & \\
$\begin{array}{l}\text { No }(\%) \\
95 \% \mathrm{Cl}\end{array}$ & $0(0)$ & $3(10)$ & $6(46)$ \\
N & 0 & $0-18$ & $19-73$
\end{tabular}

Note: $*$ The rate of objective response was defined as the percentage of patients who had a complete response or partial response.

Abbreviations: GEM, gemcitabine; GS, gemcitabine + S-I; S-I, tegafur-gimeraciloteracil potassium; $\mathrm{Cl}$, confidence interval.

patients experienced higher frequencies of thrombocytopenia, anorexia, and fatigue than those in the arm eligible.

\section{Discussion}

This retrospective study evaluated the efficacy and the safety of chemotherapy in patients with advanced pancreatic cancer in clinical practice. The median PFS was 3.5 months, and the median OS was 6.7 months in all patients. The outcome of patients who met the eligibility criteria of the clinical trial was as expected regardless of treatment: PFS was 4.5 months, and median OS was 10.5 months. On the other hand, the outcome of ineligible patients was very poor: PFS was 1.1 months, and median OS was 2.9 months. Treatment was generally well tolerated, and adverse events were manageable.

Several previous studies have reported the treatment outcome of advanced pancreatic cancer in clinical practice. ${ }^{7-12}$ In our study, patient characteristics such as age, sex ratio, PS, tumor location, and number of metastatic organs were similar to these reports in all patients. The efficacy and safety were also comparable to those reports in all patients. These previous studies identified poor prognostic factors for advanced pancreatic cancer, including a poor PS, an elevated level of C-reactive protein, an elevated level of carbohydrate antigen 19-9 at the time of diagnosis, an advanced TNM (tumor-node-metastasis) stage, and a poor nutritional status or the presence of anemia. In our study, patients who could not enroll in the clinical trial on reasonable grounds because of poor physical condition also demonstrated poor prognostic factors.

Generally, pancreatic cancer progresses rapidly, and a patient's performance status often deteriorates rapidly.
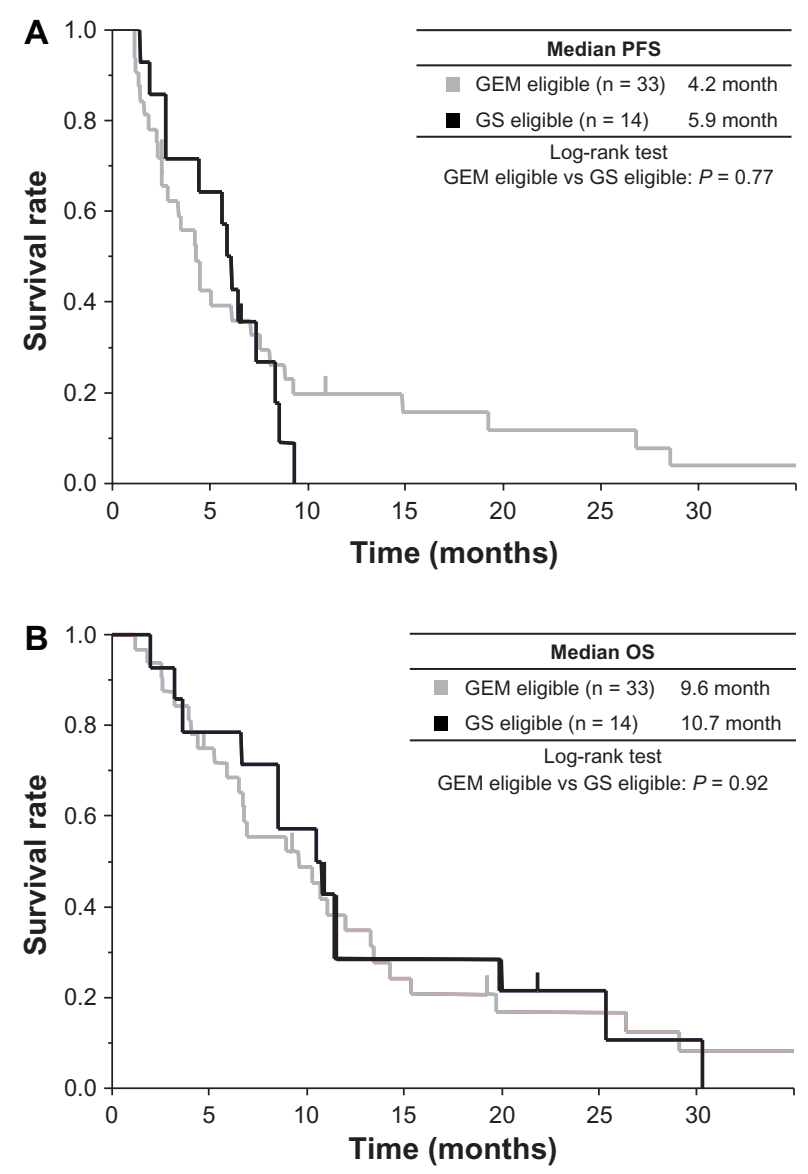

Figure 2 Kaplan-Meier estimates of PFS and OS in the clinical trial eligible group (arm eligible), according to treatment group. (A) PFS; the median was 4.2 months in GEM (gray line) and 5.9 months in GS (black line). (B) OS; the median was 9.6 months in GEM (gray line) and 10.7 months in GS (black line).

Abbreviations: PFS, progression-free survival; OS, overall survival; GEM, gemcitabine; GS, GEM + S-I (tegafur, gimeracil, and oteracil potassium).

The main reasons why patients did not meet the eligibility criteria were poor performance status and massive ascites. These patients had aggressive disease progression and/or rapid deterioration of performance status regardless of treatment with chemotherapy. Furthermore, chemotherapy should be initiated to ineligible patients more carefully than eligible patients, because ineligible patients may suffer from serious adverse effects. ASCO (American Society of Clinical Oncology) identified some key opportunities to improve care and reduce costs for oncology. ${ }^{13}$ One of these outlined the indication for chemotherapy treatment. It advised physicians not to use cancer-directed therapy for patients with solid tumors who have the following characteristics: low performance status ( 3 or 4), no benefit from prior evidence-based interventions, ineligibility for a clinical trial, and no strong evidence supporting the clinical value of further anticancer treatment. There have been few trials of chemotherapy in patients with poor PS. Two studies in lung cancer patients 
Table 3 Toxicity

\begin{tabular}{|c|c|c|c|c|c|c|}
\hline & \multicolumn{6}{|l|}{ No (\%) } \\
\hline & \multicolumn{2}{|c|}{$\begin{array}{l}\text { Arm ineligible } \\
\text { with GEM }(n=20)\end{array}$} & \multicolumn{2}{|c|}{$\begin{array}{l}\text { Arm eligible } \\
\text { with GEM }(n=33)\end{array}$} & \multicolumn{2}{|c|}{$\begin{array}{l}\text { Arm eligible } \\
\text { with GS }(n=14)\end{array}$} \\
\hline & All & Grade 3/4 & All & Grade 3/4 & All & Grade 3/4 \\
\hline \multicolumn{7}{|l|}{ Hematologic } \\
\hline Leukopenia & $10(50)$ & $4(20)$ & $22(67)$ & $6(18)$ & II (79) & $2(14)$ \\
\hline Neutropenia & $9(45)$ & $5(25)$ & $22(67)$ & $6(18)$ & $10(7 \mid)$ & $2(14)$ \\
\hline Anemia & $15(75)$ & $2(10)$ & $25(76)$ & $2(6)$ & II (79) & I (7) \\
\hline Thorombocytopenia & II (55) & $3(15)$ & $22(67)$ & $2(6)$ & $8(57)$ & $2(14)$ \\
\hline \multicolumn{7}{|l|}{ Nonhematologic } \\
\hline Anorexia & $12(60)$ & $3(15)$ & II (33) & I (3) & $9(64)$ & $2(14)$ \\
\hline Vomiting & $4(20)$ & $0(0)$ & $8(24)$ & $0(0)$ & $0(0)$ & $0(0)$ \\
\hline Constipation & $6(30)$ & $0(0)$ & $18(55)$ & $0(0)$ & $6(43)$ & $0(0)$ \\
\hline Diarrhea & $0(0)$ & $0(0)$ & $4(12)$ & I (0) & $3(2 I)$ & I (7) \\
\hline Fatigue & $12(60)$ & $2(10)$ & $12(36)$ & $2(6)$ & $9(64)$ & I (7) \\
\hline Rash & $4(20)$ & $0(0)$ & $3(10)$ & $0(0)$ & $6(43)$ & I (7) \\
\hline
\end{tabular}

Abbreviations: GEM, gemcitabine; GS, gemcitabine + S-I; S-I, tegafur-gimeracil-oteracil potassium.

with poor PS show improvement of quality of life, but median survival was very short, half that of patients of good PS. ${ }^{14,15}$ Neither of these studies had a control group. There are no published trials of chemotherapy in patients with pancreatic cancer and poor physical condition. The current result also shows that these patients do not seem to benefit from chemotherapy, and the best practice would be to provide appropriate palliative and supportive care and referral to a hospice.

On the other hand, some patients were in better physical condition in the eligible group. GS was administrated to the younger and healthier PS patients instead of GEM in our study. GS was generally well tolerated for these limited patients. More aggressive treatments such as FOLFIRINOX are necessary to provide and develop a survival benefit for the patients who have good PS and are able to tolerate toxicity.

\section{Conclusion}

The outcomes of advanced pancreatic cancer patients who met the eligibility criteria of the clinical trial were similar to GEST. Chemotherapy has an equal benefit for these patients as clinical trials, and physicians should provide treatment aggressively for them. On the other hand, survival for advanced pancreatic cancer patients who did not meet the eligibility criteria of the clinical trial was very poor. These patients may not receive a survival benefit from existing chemotherapy. Therefore, it is important to select the patients who could benefit from either chemotherapy or optimal supportive care.

\section{Disclosure}

The authors report no conflicts of interest in this work.

\section{References}

1. Matsuda T, Marugame T, Kamo K, Katanoda K, Ajiki W, Sobue T. Cancer incidence and incidence rates in Japan in 2002: based on data from 11 population-based cancer registries. Jpn J Clin Oncol. 2008; 38(9):641-648.

2. Tsukuma H, Ajiki W, Ioka A, Oshima A. Survival of cancer patients diagnosed between 1993 and 1996: a collaborative study of population-based cancer registries in Japan. Jpn J Clin Oncol. 2006;36(9):602-607.

3. Burris HA 3rd, Moore MJ, Andersen J, et al. Improvements in survival and clinical benefit with gemcitabine as first-line therapy for patients with advanced pancreas cancer: a randomized trial. J Clin Oncol. 1997;15(6):2403-2413.

4. Conroy T, Desseigne F, Ychou M, et al. FOLFIRINOX versus gemcitabine for metastatic pancreatic cancer. $N$ Engl J Med. 2011;364(19): $1817-1825$.

5. Moore MJ, Goldstein D, Hamm J, et al. Erlotinib plus gemcitabine compared with gemcitabine alone in patients with advanced pancreatic cancer: a phase III trial of the National Cancer Institute of Canada Clinical Trials Group. J Clin Oncol. 2007;25(15):1960-1966.

6. Ioka T, Ikeda M, Ohkawa S, et al. Randomized phase III study of gemcitabine plus S-1 (GS) versus S-1 versus gemcitabine (GEM) in unresectable advanced pancreatic cancer (PC) in Japan and Taiwan: GEST study. J Clin Oncol. 2011;29:abstr 4007.

7. Ueno H, Okada S, Okusaka T, Ikeda M. Prognostic factors in patients with metastatic pancreatic adenocarcinoma receiving systemic chemotherapy. Oncology. 2000;59(4):296-301.

8. Tanaka T, Ikeda M, Okusaka T, et al. Prognostic factors in Japanese patients with advanced pancreatic cancer treated with single-agent gemcitabine as first-line therapy. Jpn J Clin Oncol. 2008;38(11): 755-761.

9. Sawaki A, Kanemitsu Y, Mizuno N, et al. Practical prognostic index for patients with metastatic pancreatic cancer treated with gemcitabine. J Gastroenterol Hepatol. 2008;23(8 Pt 1):1292-1297.

10. Pine JK, Fusai KG, Young R, et al. Serum C-reactive protein concentration and the prognosis of ductal adenocarcinoma of the head of pancreas. Eur J Surg Oncol. 2009;35(6):605-610.

11. Hess V, Glimelius B, Grawe P, et al. CA 19-9 tumour-marker response to chemotherapy in patients with advanced pancreatic cancer enrolled in a randomised controlled trial. Lancet Oncol. 2008;9(2):132-138.

12. Kim ST, Choi YJ, Park KH, et al. A prognostic model to identify patients with advanced pancreas adenocarcinoma who could benefit from second-line chemotherapy. Clin Oncol (R Coll Radiol). 2012;24(2):105-111. 
13. Schnipper LE, Smith TJ, Raghavan D, et al. American Society of Clinical Oncology identifies five key opportunities to improve care and reduce costs: the top five list for oncology. J Clin Oncol. 2012;30(14): $1715-1724$.

14. Baka S, Ashcroft L, Anderson H, et al. Randomized phase II study of two gemcitabine schedules for patients with impaired performance status (Karnofsky performance status $\leq 70$ ) and advanced non-smallcell lung cancer. J Clin Oncol. 2005;23(10):2136-2144.
15. Leong SS, Toh CK, Lim WT, et al. A randomized phase II trial of singleagent gemcitabine, vinorelbine, or docetaxel in patients with advanced non-small cell lung cancer who have poor performance status and/or are elderly. J Thorac Oncol. 2007;2(3):230-236.

\section{Publish your work in this journal}

OncoTargets and Therapy is an international, peer-reviewed, open access journal focusing on the pathological basis of all cancers, potential targets for therapy and treatment protocols employed to improve the management of cancer patients. The journal also focuses on the impact of management programs and new therapeutic agents and protocols on

\section{Dovepress}

patient perspectives such as quality of life, adherence and satisfaction The manuscript management system is completely online and includes a very quick and fair peer-review system, which is all easy to use. Visit http://www.dovepress.com/testimonials.php to read real quotes from published authors.

\footnotetext{
Submit your manuscript here: http://www.dovepress.com/oncotargets-and-therapy-journal
} 